\title{
Improved Performance of Solid-State Metal Hydride Batteries Using Heteropolyacid Hydrate as an Electrolyte
}

\author{
Keisuke HATAKEYAMA, ${ }^{\mathrm{a}}$ Hiroki SAKAGUCHI, ${ }^{\mathrm{a}}$ Taku YAMAGUCHI, ${ }^{\mathrm{a}}$ Hiroshi INOUE, \\ Chiaki IWAKURA, ${ }^{\mathrm{b}}$ and Takao ESAKA ${ }^{\mathrm{a}}$
}

\author{
a Department of Materials Science, Faculty of Engineering, Tottori University (Minami 4-101, Koyamacho, Tottori 680- \\ 0945, Japan) \\ ${ }^{\mathrm{b}}$ Department of Applied Chemistry, Graduate School of Engineering, Osaka Prefecture University (1-1, Gakuencho, \\ Sakai, Osaka 599-8531, Japan)
}

Received April 27, 2004 ; Accepted July 15, 2004

\begin{abstract}
In order to enhance the electrochemical performance of our solid-state metal hydride battery using an electrolyte of heteropolyacid hydrate, such as 12-molybdophosphoric acid hydrate $\left(\mathrm{H}_{3} \mathrm{PMo}_{12} \mathrm{O}_{40} \cdot 20 \mathrm{H}_{2} \mathrm{O}\right)$, we tried to improve the total battery construction; the interface between electrode and electrolyte was increased and the electrolytic manganese dioxide was adapted as a positive electrode material instead of reagent grade manganese dioxide previously used. The resultant battery exhibited remarkably longer cycle life performance, higher discharge efficiency, and lower polarization than the previous one. The high rate charge-discharge characteristics was improved significantly by optimizing electrolyte content in the positive electrode; the battery was able to operate over 200 cycles at $10 \mathrm{~mA} \mathrm{~g}(\text { alloy })^{-1}$.
\end{abstract}

Key Words : Solid-state Battery, Heteropolyacid Hydrate, Solid Electrolyte, Metal Hydride, Manganese Dioxide

\section{Introduction}

Nickel-metal hydride $(\mathrm{Ni} / \mathrm{MH})$ batteries are widely used for portable electric devices. This is because they have excellent performances on energy and power densities, charge-discharge characteristics, and cycle life. However, considering that the commercial $\mathrm{Ni}^{\prime}{ }^{\prime} \mathrm{MH}$ batteries contain a liquid electrolyte, i.e., $\mathrm{KOH}$ aqueous solution, we have some concern about electrolyte leakage, electrolyte freezing, and dryness of separator. To solve the problems, solid-state metal hydride batteries using solid electrolytes have become of interest in recent years. Several papers have been reported as for the batteries using solid electrolytes such as $\mathrm{Sb}_{2} \mathrm{O}_{5} \cdot \mathrm{nH}_{2} \mathrm{O},{ }^{1,2)}\left(\mathrm{CH}_{3}\right)_{4}$ $\mathrm{NOH} \cdot 5 \mathrm{H}_{2} \mathrm{O}^{3-5)}$ and polymer electrolytes. ${ }^{6}{ }^{6}$ ) $)$ Iwakura et al. demonstrated that performance of the battery using polymer gel electrolyte was comparable to that of the $\mathrm{Ni} / \mathrm{MH}$ battery practically used. ${ }^{8}$ They, furthermore, reported that several tens cycles of charge-discharge was possible at a current density of $5 \mathrm{~mA} \mathrm{~g}^{-1}$ on the battery with $\mathrm{H}_{3} \mathrm{PO}_{4}$-doped silica gel electrolyte. ${ }^{9}$

In 2003, we also reported a manganese dioxide-metal hydride $\left(\mathrm{MnO}_{2} / \mathrm{MH}\right)$ battery using 12 molybdophosphoric acid hydrate $\left(\mathrm{H}_{3} \mathrm{PMo}_{12} \mathrm{O}_{40} \cdot 20 \mathrm{H}_{2} \mathrm{O}\right)$ as an electrolyte. ${ }^{10)}$ The battery was able to operate in more than 100 cycles at a current density of $5 \mathrm{~mA} \mathrm{~g}^{-1}$. The battery performance was, however, not so sufficient as the batteries practically used. In the present study, we have attempted to improve such electrochemical properties as coulomb efficiency and high rate and cycle life performances by increasing the electrode-electrolyte interface and/or employing electrolytic manganese dioxide as the positive electrode material instead of reagent grade manganese dioxide used previously.

\section{Experimental}

In order to set up experimental metal hydride batteries, a heteropolyacid hydrate of $\mathrm{H}_{3} \mathrm{PMo}_{12} \mathrm{O}_{40} \cdot 20 \mathrm{H}_{2} \mathrm{O}$ (Wako Pure Chemical Industries, Ltd.) was employed as an electrolyte without any pretreatment and a hydrogen storage alloy, $\mathrm{ZrMn}_{1 .} \mathrm{Cr}_{n} \mathrm{Ni}_{1,3}$, as an anode active material. In this case, the alloy was prepared by mixing $\mathrm{ZrMn}_{1.5} \mathrm{Cr}_{0.7}$ powder (Nilaco) with Ni powder using mechanical alloying method and, thereafter, hydrogenated using a hydrogen gas pressurizing apparatus. To get a negative electrode, the hydrogen storage alloy powder ( $c a .0 .1 \mathrm{~g}$ ), conductive material ( acetylene black), binder (polytetrafluoroethylene, PTFE) and solid electrolyte $\left(\mathrm{H}_{3}\right.$ $\mathrm{PMo}_{12} \mathrm{O}_{40} \cdot 20 \mathrm{H}_{2} \mathrm{O}$ ) were mixed thoroughly in a weight ratio of 85:5:5:5. On the other hand, two kinds of manganese dioxide powders, i.e. reagent grade manganese dioxide (Wako Pure Chemical Industries, Ltd.) and electrolytic manganese dioxide for the battery use (Mitsui Mining \& Smelting Co., Ltd.), were employed as cathode active materials. As to the positive electrode, the solid electrolyte was mixed in the same way as the negative electrode; the contents of electrolyte were varied to $5,10,20$, and 40 wt. $\%$ in accordance with that of the active materials of $85,80,70$, and 50 wt.\%.

Using the above electrolyte and electrode materials, the solid-state metal hydride battery was constructed. After setting the powder of negative electrode material into a cylinder, the electrolyte powder ( $c a .0 .25 \mathrm{~g}$ ) was uniformly loaded on it. Thereafter, the powder of positive electrode material was loaded on the electrolyte/anode layer. The piled powders were pressed by $1 \times 10^{3} \mathrm{kgf}$ $\mathrm{cm}^{-2}$ at a time to obtain a pellet with $13 \mathrm{~mm}$ in diameter. This process was completely different from the previous 
way to repeat loading and pressing each component three times in turn. The pellet was mounted in an airtight two-electrode-type cell made of stainless steel (Hosen Co., HS-type cell). The electrochemical tests were carried out at $30^{\circ} \mathrm{C}$ using the galvanostatic chargedischarge apparatus (KEISOKUKI, BS 2506) controlled by a computer. The cell was charged at 5 or $10 \mathrm{~mA} \mathrm{g(al-}$ loy) ${ }^{-1}$ for $1 \mathrm{~h}$, and discharged in the same manner down to $0.4 \mathrm{~V}$. A ten-minute break was set after every charging and discharging.

\section{Results and Discussion}

Figure 1 comparatively shows the 50th chargedischarge curves for the $\mathrm{MnO}_{2}$ (reagent grade)/ $\mathrm{MH}$ test cells obtained in two different pressing methods. The cell using one-step press in the present study showed lower overvoltage and longer discharge time as compared with the previous battery prepared by three-steps press. This would be due to that the cell constructed in this study had a rough electrode/electrolyte interface to smooth the electrode reaction. Figure 2 shows the discharge efficiency variations of the two types of cells. Here, the efficiency is the ratio of the measured discharge capacity to the charge capacity. The efficiency increased by about $5 \%$ and the cycle life performance was improved slightly in the case of one-step press. However, this cycle life

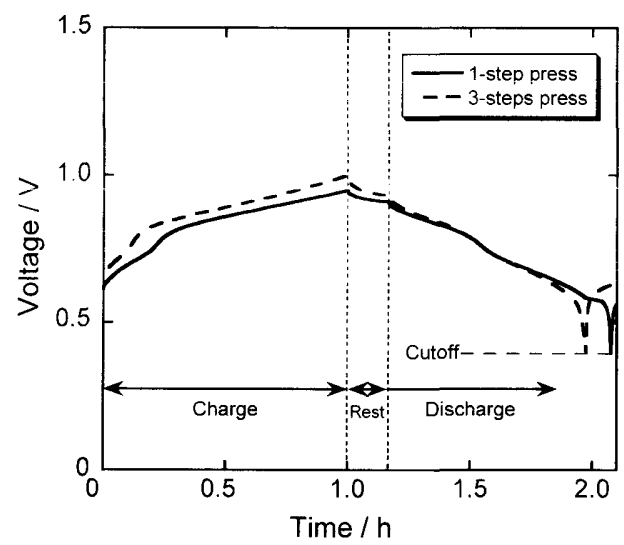

Fig. 1 The 50th charge-discharge curves for the cell, $\mathrm{ZrMn}_{1.5}$ $\mathrm{Cr}_{0.7} \mathrm{Ni}_{0.3} \mathrm{H}_{\mathrm{x}} / \mathrm{H}_{3} \mathrm{PMo}_{12} \mathrm{O}_{40} \cdot 20 \mathrm{H}_{2} \mathrm{O} / \mathrm{MnO}_{2}$ (regent grade), obtained in two different pressing methods. Charge and discharge current densities are $5 \mathrm{~mA} \mathrm{~g}$ (alloy) ${ }^{-1}$.

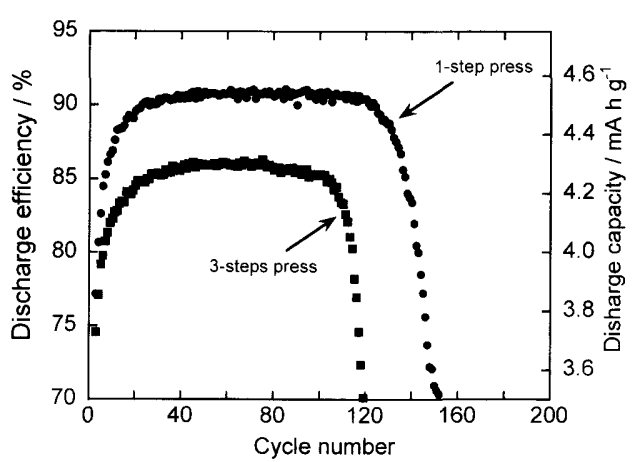

Fig. 2 Discharge efficiency variations with the cycle numbers for the following cell, $\mathrm{ZrMn}_{1.5} \mathrm{Cr}_{0.7} \mathrm{Ni}_{0.3} \mathrm{H}_{\mathrm{x}} / \mathrm{H}_{3} \mathrm{PMo}_{12} \mathrm{O}_{40} \cdot 20$ $\mathrm{H}_{2} \mathrm{O} / \mathrm{MnO}_{2}$. Charge and discharge current densities are 5 $\mathrm{mA} \mathrm{g}$ (alloy) ${ }^{-1}$. performance was not still sufficient.

We supposed that the poor cyclability of the cell might be due to cathode material. Considering the following reaction occurs on $\mathrm{MnO}_{2}$ electrode in acid electrolyte,

$$
\mathrm{MnO}_{2}+\mathrm{H}_{3} \mathrm{O}^{*}+\mathrm{e} \quad \cdot \mathrm{MnOOH}+\mathrm{H}_{2} \mathrm{O}
$$

the low reactivity with protons and the subsequent low proton diffusivity would cause severe problems. In fact, the our previous cell generated a high overvoltage, which increased remarkably with charge-discharge cycling. ${ }^{10)}$ Thus, we changed the cathode material from the reagent grade manganese dioxide to the electrolytic manganese dioxide for commercial batteries. Figure 3 shows the variations of the discharge efficiency with chargedischarge cycling. It is noteworthy that the discharge efficiency comes up to about $90 \%$. Moreover, the cell cycle life extends to about 450 cycles. Figure 4 gives the 50 th and 450th charge-discharge curves of the present cell. In the previous cell using the reagent grade manganese dioxide, ${ }^{10)}$ the terminal voltage exceeded $1.4 \mathrm{~V}$ at the end of the 150th charge. As for the present cell using the electrolytic manganese dioxide, the polarization was not so high even at 450 cycles. These facts indicate the smooth electrode reaction on the cathode and suggest that the diffusion of proton into the electrode bulk is very important to improve the cycle life performance. On

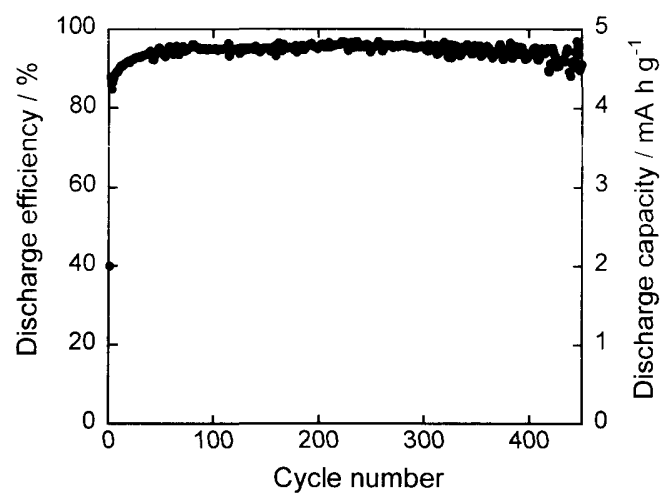

Fig. 3 Discharge efficiency variation with the cycle numbers for the battery using electrolytic manganese dioxide as a positive electrode material. Charge and discharge current densities are $5 \mathrm{~mA} \mathrm{~g}$ (alloy) ${ }^{-1}$.

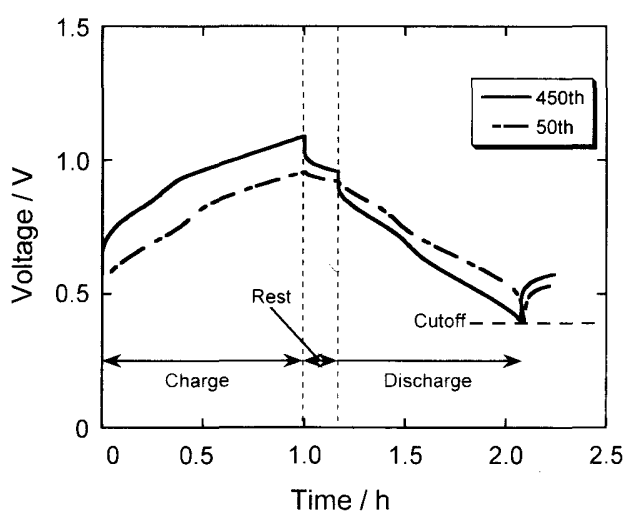

Fig. 4 Charge-discharge curves for the battery using electrolytic manganese dioxide as the positive electrode material. Charge and discharge current densities are $5 \mathrm{~mA} \mathrm{g(alloy)}{ }^{-1}$. 


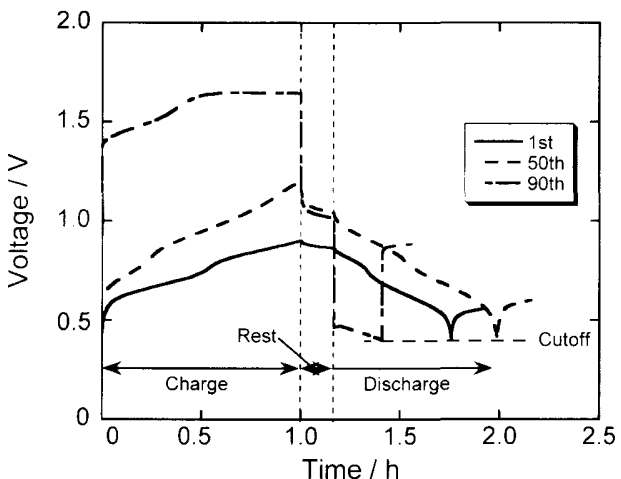

Fig. 5 Charge-discharge curves for the battery using electrolytic manganese dioxide at a higher current density of $10 \mathrm{~mA}$ g(alloy) ${ }^{-1}$.

the contrary, considering that the average valence states of manganese were 3.75 in the regent grade manganese dioxide and 3.92 in the electrolytic manganese dioxide, the proton diffusion might be disturbed by manganese sesqui-oxide partly present in the regent grade manganese dioxide as was generally known.

Here, we additionally checked influence of the atomospheric humidity on cell performance, considering the hydrate electrolyte. After the usual charge-discharge test (200 cycles at a current density of $5 \mathrm{~mA} \mathrm{~g}$ (alloy) ${ }^{-1}$ ), the test cell was unpacked and left in the atmosphere for 30 days. Thereafter, the battery performance was tested again. As a result, the discharge efficiency was almost the same as before, which exhibited that the battery was not influenced so much by usual humidity and temperature change. This result may be favorable for the easy treatment and storage of the batteries.

Next, we tested the cyclability of the cell with a higher current density of $10 \mathrm{~mA} \mathrm{~g}$ (alloy) ${ }^{-1}$. As a result, it was found that the discharge efficiency decreased to $80 \%$ accompanying the cell life terminated within 100 cycles. Figure 5 shows the 1st, 50th and 90th charge-discharge curves, where the quite high overvoltage appeared in the 90th charge and discharge curves. This suggested that the amount of electrode/electrolyte interface, i.e. the reaction area, was not enough against the current density.

To improve the high rate charge-discharge characteristics, we attempted to increase the interface area by changing the content of solid electrolyte in the positive electrode from $5 \mathrm{wt} . \%$ to 10,20 and $40 \mathrm{wt} . \%$. The discharge efficiencies for the cells tested at a current density of $10 \mathrm{~mA} \mathrm{~g}$ (alloy) $^{-1}$ are shown in Fig. 6. The cycle life was extremely improved by increasing the electrolyte contents up to $40 \mathrm{wt} \%$; the cell was able to operate over 200 cycles maintaining the discharge efficiency about 95 $\%$ and the rest voltage almost the same as that at the end of charging. This implied importance of the optimization of the electrode/electrolyte interface to improve the cell performance. Considering the above results, the present battery performance was superior to that of the $\mathrm{MnO}_{2} / \mathrm{MH}$ solid-state battery using $\mathrm{Sb}_{2} \mathrm{O}_{5} \cdot \mathrm{nH}_{2} \mathrm{O}^{1}$ ) or $\left(\mathrm{CH}_{3}\right)_{4} \mathrm{NOH} \cdot 5 \mathrm{H}_{2} \mathrm{O}^{3-5)}$, and was comparable to that of the $\mathrm{Ni} / \mathrm{MH}$ solid-state battery using $\mathrm{H}_{3} \mathrm{PO}_{4}$-doped silica gel. ${ }^{9)}$

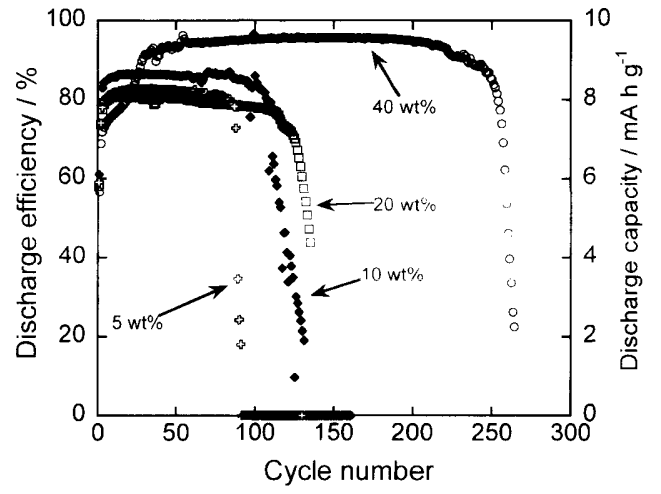

Fig. 6 Discharge efficiency variations with the cycle numbers for the battery with different electrolyte contents in the positive electrode. Charge and discharge current densities are $10 \mathrm{~mA} \mathrm{~g}$ (alloy) ${ }^{-1}$.

\section{Conclusions}

The performance of solid-state $\mathrm{MnO}_{2} / \mathrm{MH}$ battery using 12-molybdophosphoric acid hydrate $\left(\mathrm{H}_{3} \mathrm{PMo}_{12} \mathrm{O}_{40} \cdot 20\right.$ $\mathrm{H}_{2} \mathrm{O}$ ) as an electrolyte was enhanced by improvement of pressing method and employment of electrolytic manganese dioxide. The discharge efficiency came up to about $90 \%$ and the cell cycle life extended to about 450 cycles. The high rate characteristic of the battery was improved significantly by optimizing the electrolyte content in the positive electrode; the battery was able to operate over 200 cycles at $10 \mathrm{~mA} \mathrm{~g}$ (alloy) ${ }^{-1}$ and keep the discharge efficiency about $95 \%$. In addition, the battery performance varied scarcely after exposure to the atmosphere for a long time.

\section{Acknowledgments}

This work has been partially supported by a Grant-inAid for Scientific Research on Priority Areas of "Ionics Devices" from the Ministry of Education, Science, Sports and Culture of Japan.

\section{References}

1) M. Mohri, Y. Tajima, H. Tanaka, T. Yoneda, and M. Kasahara, Sharp Tech. J., 34, 97 (1986).

2) T. Yoneda, S. Satoh, and M. Mohri, Sharp Tech. J., 38, 55 (1987) 55.

3) N. Kuriyama, T. Sakai, H. Miyamura, A Kato, and H. Ishikawa, Denki Kagaku (presently Electrochemistry), 58, 89 (1990).

4) N. Kuriyama, T. Sakai, H. Miyamura, A Kato, and H. Ishikawa, J. Electrochem. Soc., 137, 355 (1990).

5) N. Kuriyama, T. Sakai, H. Miyamura, A Kato, and H. Ishikawa, Solid State Ionics, 40/41, 906 (1990).

6) N. Vassal, E. Salmon, and J.-F. Fauvarque, J. Electrochem. Soc., 146, 20 (1999).

7) N. Vassal, E. Salmon, and J.-F. Fauvarque, Electrochim. Acta, 45, 1527 (2000).

8) C. Iwakura, S. Nohara, N. Furukawa, and H. Inoue, Solid State Ionics, 148, 487 (2002).

9) C. Iwakura, K. Kumagae, K. Yoshiki, S. Nohara, N. Furukawa, H. Inoue, T. Minami, M. Tatsumisago, and A. Matsuda, Electrochim. Acta, 48, 1499 (2003).

10) K. Hatakeyama, H. Sakaguchi, K. Ogawa, H. Inoue, C. Iwakura, and T. Esaka, J. Power Sources, 124, 559 (2003). 